\title{
Remediation of Organic Contaminants in Groundwater
}

\author{
Bernard H. Kueper \\ Department of Civil Engineering, Queen's University \\ Kingston, Ontario, Canada K7L 3N6 \\ Kueperb@queensu.ca
}

Organic contaminants such as chlorinated solvents, creosote, coal tar, polychlorinated biphenyls and fuels have resulted in adverse impacts to groundwater at numerous sites world-wide. These compounds are immiscible in water and are broadly classified as non-aqueous phase liquids (NAPLs). Because NAPLs have low solubility in water, they can persist for decades to hundreds of years in the subsurface. Remediation of NAPL-impacted sites remains technically challenging, costly and contentious in terms of the expectations of various stakeholders associated with any given site.

Experience has shown that making progress towards remediation of NAPL-impacted sites often requires stakeholders to develop realistic expectations regarding the ability to remediate chlorinated solvent source zones. Experience also has shown that an adaptive management strategy often leads to the most efficient treatment. These lessons will be valuable as the focus increasingly shifts to remediation of the most complex sites, which include NAPL source zones in fractured bedrock and dissolved phase contaminants stored in low permeability media. Remediation technology application and assessment has not progressed from simple sites to complicated sites. Rather, remediation technologies have been applied at a wide range of sites exhibiting various levels of complexity, resulting in ambiguous interpretations of technology performance.

This talk will discuss key issues regarding remediation of NAPL-impacted sites. Specific topics addressed include source zone characterization and the need to determine at which life-cycle stage the source zone exists, plume response to mass removal in various geological settings, and the use of in-situ thermal treatment (ISTT) for NAPL removal. 